\title{
Explicit and implicit ethical issues in the reports of the Intergovernmental Panel on Climate Change: the example of the "tipping points" metaphor
}

Questions éthiques explicites et implicites dans les rapports du GIEC : l'exemple de la métaphore des " points de bascule»

\section{Marie-Hélène Fries}

\section{OpenEdition}

\section{Journals}

\section{Electronic version}

URL: https://journals.openedition.org/asp/5945

DOI: 10.4000/asp.5945

ISSN: 2108-6354

\section{Publisher}

Groupe d'étude et de recherche en anglais de spécialité

\section{Printed version}

Date of publication: 1 November 2019

Number of pages: 9-27

ISSN: 1246-8185

\section{Electronic reference}

Marie-Hélène Fries, "Explicit and implicit ethical issues in the reports of the Intergovernmental Panel on Climate Change: the example of the "tipping points" metaphor", ASp [Online], 76 | 2019, Online since 01 November 2020, connection on 29 November 2021. URL: http://journals.openedition.org/asp/5945 ; DOI: https://doi.org/10.4000/asp.5945

This text was automatically generated on 29 November 2021.

Tous droits réservés 


\section{Explicit and implicit ethical issues in the reports of the Intergovernmental Panel on Climate Change: the example of the "tipping points" metaphor}

Questions éthiques explicites et implicites dans les rapports du GIEC : l'exemple de la métaphore des "points de bascule»

\section{Marie-Hélène Fries}

\section{Introduction}

1 The issue of anthropogenic climate change first came into the limelight in 1975, with the publication of a research article by Wallace Smith Broecker, a geochemist at Columbia University, entitled "Climatic change: Are we on the brink of a pronounced global warming?." It has since developed into a large interdisciplinary research area ranging from climate sciences to economics, which has also involved the development of myriads of conferences (including the UN Conferences of the Parties) and publications, among which a new journal introduced by Nature, called Nature Climate Change. All this research work has fostered a growing awareness of the human-induced nature of climate change in public opinion worldwide and in political circles. The United Nations, in particular, has been playing an active role in climate change mitigation both politically, from the United Nations Framework Convention on Climate Change (1992) and the subsequent Conferences of the parties (COP) to other international treaties, and scientifically, with the creation of the International Panel of Climate Change (IPCC) by the United Nations in 1988. 
2 Three intertwined ethical issues have dominated climate change debates since the 1980s, to the point of brewing up "A Perfect Moral Storm", as outlined by Stephen Gardiner (2011). The first two challenges are deontic ${ }^{1}$ and deal with injustice. Although climate change is a global phenomenon, its effects are not felt in the same way in all the different parts of the world. Moreover, the countries that suffer most from droughts, floods or extreme weather events, such as tornadoes or landslides, are often precisely the ones that have least contributed to the increase of greenhouse-effect gases in the atmosphere ${ }^{2}$. This challenge of "skewed vulnerabilities" has direct consequences in terms of political justice and is recurrent in all the international talks on climate change. A second deontic problem deals with intergenerational imbalance worldwide. Because greenhouse gases (GHGs) remain in the atmosphere for years before being absorbed (up to a hundred years for carbon dioxide, for example), we are already starting to feel the effects of accumulated past GHG emissions, which are likely to worsen for future generations if efforts to lower emissions remain off the mark. This amounts to an "intergenerational arms race." The third main ethical challenge linked to climate change is epistemic and deals with uncertainty as well as with the inadequacies of the models used to forecast climate change. They all include built-in limitations, since modelling always involves simplifying reality, with the risk of leaving out essential parameters. Other shortcomings of models are contingent and depend either on lack of computer power or human unpredictability. This potential lack of reliability in models prompts the question of the usefulness of the precautionary principle and the relevance of preventive measures, even in the absence of absolute certainty.

3 More pragmatically, ethical issues in climate justice can also be seen to function either explicitly, through the open expression of values, or implicitly, in narratives for example, as pointed out by the French philosopher Paul Ricœur. In Ricœur's view, narratives can convey ethical values implicitly, because they form a middle ground between description and prescription (1990: 200). An implicit expression of values can also be found in metaphors, as "virtually all of our abstract moral concepts are structured metaphorically" (Lakoff \& Johnson 999: 290). This divide between explicit and implicit ethics is routinely experienced in specialised domains, where employees and professionals, whether they work in small consultancies, large companies or international institutions, behave more often than not according to an internal set of values which is reflected in their oral exchanges and their writings, even in work contexts when there are no explicit codes of conduct or value-laden statements.

4 In order to examine the relevance of moral issues in the climate change research area, as far as professional ethics are concerned, we first need to show in which ways climate change is linked to specialised domains and explain to what extent the IPCC Assessment Reports (ARs) ${ }^{3}$ are representative of a climate change discourse community.

5 The concept of domain is used in several linguistic areas, including terminology (where they are part of the definition of terms) and cognitive semantics (in which metaphors are defined as based on analogy, or "conceptual mappings" projected from the source domain to the target domain (Lakoff \& Johnson 1980). As far as the study of specialised varieties of English is concerned, the following definition, given by Michel Petit, seems the most operational: "a specialised domain is formed around and in view of a main activity, which defines its recognisable place in society" (Petit, 2010: \$20). ${ }^{4}$ The IPCC can be considered as the prototypical part of the climate change community, because it is 
widely recognised both by climate change specialists worldwide and by politicians and the general public. As stated on the internet site, its main missions are thus to assess the state of the climate and to update its evaluation on a regular basis:

The IPCC was created to provide policymakers with regular scientific assessments on climate change, its implications and potential future risks, as well as to put forward adaptation and mitigation options (IPCC home page)

These main activities seem very similar to those of doctors, who also give their patients scientific assessments on their health (i.e. diagnoses) and suggest mitigation options in the form of prescriptions. However, unlike medicine, which involves only professionals receiving a standardized education, with a well-defined place in society, climate change experts do not form a homogeneous practice community: they may have been trained as glaciologists or oceanographers as well as economists or even political scientists. In other words, climate change seems to be at the crossroads of specialised domains of different types, both professional (politics) and disciplinary (climate science), as the glossaries of the IPCC reports show (see Fries forthcoming). Additional criteria may help us to decide on the nature of anthropomorphic climate change. According to Petit (2010), specialised domains are structured through three main functions: operations, regulations and training. The elaborate drafting and reviewing processes developed by the IPCC for its Assessment Reports can also be considered a unified regulatory procedure. However, the working methods and processes developed and implemented by the climate change experts really depend on their fields of research and show no unity, apart from a generalised use of models. We could therefore tentatively conclude that human-induced climate change is a specialised domain "of the third type", a category provided by Petit (2010) alongside disciplinary and professional domains, to account for less typical cases.

7 Climate change has attracted the attention of linguists interested in specialised domains (see for instance Wozniak \& Biros, 2016; Fløttum 2017), and this for two main reasons. First of all, because it is related to political at least as much as to scientific issues, it has a broad coverage in the media as well as in specialised journals and also reaches the general public. This implies that discursive genres dealing with climate change range from scientific journals (Van der Hel et al. 2016) and the IPCC reports (Fløttum 2014) to newspapers (Peynaud 2018), blogs (Biros 2018) and even specialised fiction (Biros 2010). Secondly, climate change is not universally agreed on (mainly because of the huge vested interests tied to the carbon-based economy and the uncertainties underlying climate modelling). As a consequence, it is linked to a wide range of different views and opinions (Hulme 2009), which provides researchers with interesting material for the study of debates and disagreement in specialised domains (Nehrlich et al. 2010).

The IPCC Assessment Reports seem a relevant corpus to explore climate change as a specialised domain, because they are representative of this field, both internationally and diachronically. They are collectively written by experts all over the world (more than 1,000 contributing authors and around 2,000 expert reviewers for AR5, for example). They also contain summaries for policy-makers which are subjected to a lineby-line approval process in which most UN countries take part. As a matter of fact, five full Assessment Reports have been published at regular intervals since 1988 (in 1990, 1995, 2001, 2007, and 2014), which amounts to a total of about ten million words. This 
regular updating means that the IPCC reports can also be used as a diachronic corpus, to study the evolution of climate change as a specialised body of knowledge.

If we now come back to professional ethics, taking the example of the IPCC AR reports, written by climate change experts, it looks as though two dichotomies need to be taken into account: deontic vs epistemic and explicit vs implicit. The first one refers to different ways of looking at ethical issues in general, whereas the second one seems to be especially relevant in professional ethics, as doctors, scientists or managers, although they do not always have time to reflect on ethical issues, nevertheless most often act, speak and write according to specific values and professional rules. If we now focus on the explicit versus implicit distinction in professional ethics, we first need to see if there is an explicit ethical or moral stance contained in the IPCC reports and in which ways it can be considered specific to climate change. Then we should consider whether there are any implicit ethical points of view in the IPCC reports, and, if so, whether they can be expressed through metaphors, particularly metaphors which are constitutive of climate change theories. In order to answer these research questions, we first analyse the explicit ethical dimension of the five reports by monitoring the frequency and contexts of use of the words beginning with "ethic" and "moral" in this corpus. Then we explore the usefulness of metaphors and, more particularly, theoryconstitutive metaphors, for revealing implicit ethical perspectives in the IPCC reports. The relevance of these theory constitutive metaphors in terms of professional or scientific ethics is finally illustrated with the example of the "tipping point" metaphor, its frequency throughout the five reports and its contexts of use.

\section{Explicit ethical points of view in the IPCC reports}

10 In this article, the word "ethics" has been used rather than "morals" up to now, mainly to avoid the derogatory overtones linked to the adjective "moralistic". However, there is no real reason to limit an enquiry about the explicit ethical viewpoints contained in the IPCC reports to the "ethics" word family. "Moral" and derivatives should also be included, since, etymologically, both mores in Latin and $\tilde{\hat{\eta}} \theta$ o in Greek mean customs. ${ }^{5} \mathrm{~A}$ search for "ethic" and "moral" in the five reports (thanks to Lawrence Antony's Antconc concordance software) shows a definite upward trend, from a single reference to "moral" in AR1, to 109 occurrences of moral/morally and 471 hits for ethics/ethical/ ethically in AR5 (which contains over two thirds of all the occurrences), in spite of notable fluctuations. This increasing use of words from the moral sphere therefore seems to reflect a rising awareness of ethical issues in climate change communities. A glance at table 1 shows that the IPCC experts, on the whole, seem to have a clear preference for the words "ethical" (49\%), "ethics" (32\%) and "moral" (17\%) and that two thirds of all occurrences are gathered in AR5. In view of these global results, we will now focus on the use of these three words in the fifth Assessment Report.

Table 1: Explicit references to ethics and morals in the IPCC ARs

\begin{tabular}{|l|l|l|l|l|l|l|}
\hline & AR1 (1990) & $\begin{array}{l}\text { AR2 } \\
(1995)\end{array}$ & $\begin{array}{l}\text { AR3 } \\
(2001)\end{array}$ & $\begin{array}{l}\text { AR4 } \\
(2007)\end{array}$ & $\begin{array}{l}\text { AR5 } \\
(2014)\end{array}$ & Total \\
\hline ethics & 0 & 17 & 27 & 18 & 197 & $259(31.3 \%)$ \\
\hline
\end{tabular}




\begin{tabular}{|l|l|l|l|l|l|l|}
\hline ethical & 0 & 80 & 36 & 31 & 264 & $411(49.7 \%)$ \\
\hline ethically & 0 & 5 & 0 & 0 & 5 & $10(1.2 \%)$ \\
\hline moral & 1 & 14 & 14 & 8 & 105 & $142(17.1 \%)$ \\
\hline morally & 0 & 0 & 1 & 0 & 4 & $5(0.6 \%)$ \\
\hline morals & 0 & 0 & 1 & 0 & 0 & $1(0.1 \%)$ \\
\hline Total & 1 & 116 & 79 & 57 & $575(69.5 \%)$ & $\begin{array}{l}828 \\
(100 \%)\end{array}$ \\
\hline
\end{tabular}

11 The tables of contents seem a suitable place to start, since they provide a synthetic view of the general structure of the reports. Neither "ethics", nor "ethical" or "moral" are mentioned in The physical science basis of climate change (WG1), or the Synthesis (AR1). The report of the second working group, which deals with impacts, adaptation and vulnerabilities (WG2) contains a sub-section on "ethics" (AR5 WG2: 205), while the third report on mitigation contains a whole chapter entitled "Social, Economic, and Ethical Concepts and Methods", including a subsection on "causal and moral responsibility" (AR5 WG3: 207-282). This chapter and subsections deal with deontic issues (inter and intra-generational justice), as well as with technological choices, through a presentation of the pros and cons of geoengineering (i.e. human large-scale manipulation of the climate system in order to counter some of the effects of GHGs, without cancelling them). This bird's eye view through the contents page is confirmed by frequency counts, as shown in Table 2. Overall, one third of occurrences are linked to the issue of adaptation (WG2) and two thirds to mitigation (WG3). This distribution of occurrences seems to be directly linked to the themes of the report, as mitigation is directly linked to environmental policies and related ethical considerations, whereas the physical basis of climate change deals with a different overall perspective (except for geoengineering), and issues linked with impacts and adaptation lie somewhere in the middle.

Table 2: Occurrences of "ethics", "ethical" and "moral" in AR5

\begin{tabular}{|l|l|l|l|l|}
\hline & Working Group 1 & Working Group 2 & Working Group 3 & Synthesis \\
\hline ethics & 0 & 81 & 115 & 1 \\
\hline ethical & 2 & 69 & 183 & 10 \\
\hline moral & 1 & 40 & 63 & 1 \\
\hline Total & $3(0.5 \%)$ & $190(33.5 \%)$ & $361(64 \%)$ & $12(2 \%)$ \\
\hline
\end{tabular}

12 If we now focus on the report on mitigation in AR5 - considering it seems to be the most relevant one as far as the ethical sphere is concerned - concordance lines display almost $40 \%$ of references to research articles or specialised books containing "ethics" in 
their titles (80 out of 198), 20\% including "moral" (16 out of 79 ) and 16\% with "ethical" (26 out of 162). References apart, concordance lines also show the words ethics, ethical and moral used in fairly general contexts, such as climate/environmental/ individualistic ethics, ethical constraints/considerations/ dimensions, or moral hazards/ principles/thresholds.

The study of the words ethics, ethical and moral in the IPCC reports has therefore yielded interesting results. It has shown the rising importance of an explicit ethical stance, as shown in the significant increase of occurrences of these words from 1990 to 2014. It also points to the role of the IPCC as a scientific panel in charge of advice to policy makers, as reflected by the higher number of occurrences in the report on mitigation (AR5 WG3) and in the deontic nature of most of the ethical issues discussed. However, most references to ethics remain quite abstract (as shown on the first ten concordance lines for ethic* and moral*). The adjectives "ethical" and "moral", more particularly, are followed on these examples by abstract nouns such as constraints, considerations, dimensions, duties or hazard.

Table 3: ethic* and moral* as key-words in context

\begin{tabular}{|c|c|}
\hline and priorities, based on & ethical, psychological, cultural or social \\
\hline are impractical due to & ethical constraints, the large area \\
\hline factors $\backslash x 97$ including uncertainty, & ethical considerations and links to \\
\hline the importance of governance, & ethical dimensions, equity, value judgments, \\
\hline of several normative disciplines. & Ethics analyses the different values \\
\hline . Economic methods can reflect & ethical principles, and take account \\
\hline within wider policy and & ethical frameworks to assess tradeoffs \\
\hline they therefore depend on & ethical considerations, especially on the \\
\hline Perfect Moral Storm: The & Ethical Tragedy of Climate has \\
\hline , D.G. (ed.), 2011: The & Ethics of Global Climate Change. \\
\hline ssistance; crop insurance Creates & moral hazard and distributional inequalities \\
\hline .M. (ed.), 2011: A Perfect & Moral Storm: The Ethical Tragedy \\
\hline on effective responsible and “ & moral" decision making and action, \\
\hline gration into 2010), consideration of & moral duties toward species (Sandler, 2009), \\
\hline Ethics: Navigating the Perfect & Moral Storm. Taylor 62-8 \\
\hline , S.M., 2011: A Perfect & Moral Storm: The Ethical Tragedy \\
\hline . Gonzalez-Alonso, and M. & Morales-Rivas, 2011: Characterising Pie \\
\hline
\end{tabular}




\begin{tabular}{|l|l|}
\hline of farmers' with a & moral economy. Economic Development and \\
\hline . M.I. Minguez, P. & Morales, J.P. Palutikof, M. \\
\hline generally agree economics with & moral and political philosophy (Dietz \\
\hline
\end{tabular}

In order to build a more precise and concrete picture of moral and ethical dilemmas in the IPCC reports and see in which ways they are specific to anthropogenic climate change, either as a phenomenon to be understood or as a political issue to be tackled, we therefore need to turn to implicit ethics.

\section{Implicit ethics, metaphorical terms and theory- constitutive metaphors in the IPCC reports}

15 In this article, explicit references to ethics have been defined so far, quite simply, as occurrences of the word "ethics", its derivatives or synonyms, in the ARs. More often than not, though, ethics is referred to implicitly, i.e. through values. On the official IPCC site, for example, the mission statement is defined in the following way:

An open and transparent review by experts and governments around the world is an essential part of the IPCC process, to ensure an objective and complete assessment and to reflect a diverse range of views and expertise. (IPCC home site)

16 In this mission statement, the adjectives (open, transparent, essential, objective, complete, diverse) reflect a set of values defining a working method. It can therefore be regarded as a statement expressing professional ethics.

17 A comprehensive analysis of the values expressed in the IPCC AR reports would be beyond the scope of this article. However, values can also appear indirectly through discourse features such as narration or metaphors, as stated at the beginning of this article. In the context of the IPCC reports, which are collectively written by experts from all over the world, narratives are uncommon because of a mainly descriptive or argumentative style, and creative metaphors seem too idiosyncratic and linked to individual researchers to yield generalisable results on the ethics of climate change. Metaphorical terms, on the other hand, are much more stable, because they are a specific subset of terms, which are shared by discourse communities to name phenomena linked to specialised domains (climate change, in our case). Metaphorical terms can be defined as a type of catachresis, i.e. an extension of the meaning of a word to a specialised domain in order to name a new object or concept.

The identification of metaphorical terms in the IPCC reports is made easier by the fact that they contain glossaries, which reflects the double communicative perspective of these reports. On the one hand, these glossaries are written by the authors themselves, so they express a worldwide consensus of experts on the definitions given for the entries but, on the other hand, they are aimed at the readers of the ARs, to help them understand key concepts of climate science. Therefore the glossaries also reflect the popularising purpose of the IPCC reports, which are written by specialists, but aimed at policy makers and the general public at large. If we assume that the glossaries contained in the IPCC ARs reflect a consensus of which terms are considered essential, not only in the reports themselves but also, more generally, in climate science, these 
glossaries can be taken as a basis to identify metaphorical terms, using the Metaphor Identification Protocol defined in cognitive semantics. This protocol is based on establishing the meaning of each lexical unit in context, in order to "determine if it has a more basic contemporary meaning in other contexts than the one in the given context". The word "pattern", for instance, originally referred to repeated coloured shapes printed on clothes, so we could consider "climate pattern" as a metaphor. The first meaning for "pattern" in the Cobuild dictionary, however, "a particular way in which something is done or organised", makes no mention of clothing. On the contrary, it is quite similar to the definition given in the glossary of the first working group in AR5: "A set of spatially varying coefficients obtained by "projection" (regression) of climate variables into a climate index time series (WG1AR5, p.1451). According to the MIP protocol, "climate pattern" cannot therefore be considered a metaphorical term. After this first identification stage, the researchers then need to "decide whether the contextual meaning contrasts with the basic meaning, but can be understood in comparison with it", in order to characterise this lexical unit as metaphorical (Pragglejazz group 2007: 3).

An analysis of the entries of the glossaries in AR5 yields 175 metaphorical terms out of 1,200 , i.e. around $15 \%$ (see Fries forthcoming). These metaphorical terms can be sorted into two main categories, depending on whether the catachreses are based on similarity or analogy. Instrumental catachreses, on the one hand, are based on similarities of shape ("ice cap", for instance), or anthropomorphisms and zoomorphisms (such as "ice calving" or "scenario family"). Heuristic catachreses, on the other hand, are based on analogies of function ("greenhouse effect", for example), conceptual metaphors (e.g. "time horizon") or theory constitutive metaphors (such as balance or scenario). Lakoff and Johnson's conceptual metaphors played a major role in what could be called a "cognitive turn" in metaphor studies, because the authors posit that metaphors shape the way we think before influencing the way we speak. In Lakoff and Johnson's words: "the essence of metaphors is understanding and experiencing one kind of thing in terms of another" (1980: 5). The theory of conceptual metaphors is quite wide-ranging, including pictures and gestures as well as words, specialised domains as well as literature or everyday life. Theory-constitutive metaphors, on the other hand, which have been used in the analysis of specialised varieties of English (Resche 2012; Fries 2016) as well as in terminology (Rossi 2015), are more specific to sciences, because they provide an insight into theories for lay people and a road to discovery for experts, as William Boyd insightfully shows:

The utility of theory-constitutive metaphors seems to lie largely in the fact that they provide a way to introduce terminology for features of the world whose existence seems probable, but many of whose fundamental properties have yet to be discovered. Theory-constitutive metaphors, in other words, represent one strategy for the accommodation of language to as yet undiscovered causal features of the world. (1993 [1979]: 483)

Turning from explicit to implicit ethics has thus led us to focus on metaphorical terms in the IPCC reports, because these terms are shared by climate change experts, and insights gained from them can be considered typical of this specialised domain. In the context of climate change ethics, metaphorical terms which can both be traced back to conceptual metaphors and function as theory-constitutive metaphors seem particularly relevant, because they can be used as bridges between science (and the development of specialised theories), on the one hand, and the general public (who share ethical 
concerns with scientists), on the other. A typical example of this sub-set of metaphorical terms could be the "tipping-point" metaphor, which has also been identified as a conceptual metaphor and theory-constitutive device by Gerard Steen and his team (Van der Hel et al., 2016) and will be the focus of our inquiry in the last part of this article.

\section{3. "Tipping points" and implicit ethics in the IPCC Assessment Reports}

21 "Tipping point" is linked to the balance metaphor which is pervasive in climate change (see for example Shaw \& Nerlich 2015; Deignan 2017). In everyday language, it is a vivid concrete word referring to life experiences in which a small amount of energy can trigger a loss of balance for a given overloaded object (a seesaw or a vehicle, for example). "Tipping" point in climate science is thus a space metaphor in which a physical object falling out of balance in the source domain maps onto abrupt change in the climate system. The analogy between space and climate change unfolds according to several inferences (see Figure 1). First of all, just as a force is needed in order to throw a physical object out of balance, tipping points are part of human-induced climate change, i.e. they are triggered by human activities. This point is exemplified in AR5 with two regional examples, the North Pole and the Amazon Basin, as can be seen in the following passage:

The forests of the Amazon Basin are being altered through severe droughts, land use (deforestation, logging), and increased frequencies of forest fire. Some of these processes are self-reinforcing through positive feedbacks and create the potential for a large-scale tipping point. (AR5 WG2A: 309)

Secondly, what is really specific about tipping points is that they refer to that precise point in space where only a minor impetus will be enough to trigger the loss of balance. The reasons why minor disturbances might be enough to cause a major climate change are explained in detail in AR5:

The third type is caused by system dynamics: the point at which the net effect of all the positive and negative feedback loops regulating the system is sufficiently large and positive that a small transgression becomes sufficiently amplified to lead to a change in ecosystem state called a regime shift (Lenton et al., 2008)[...]. This type of threshold is called a "tipping point". (AR5 WG2A: 278)

23 Finally, because a tipping point leads to a new stable state, forces are needed to help a physical system revert to its original state. Tipping points therefore imply potential irreversibility. In AR5, this issue is explored through the concept of hysteresis, as regards climate change:

A number of components or phenomena within the Earth system have been proposed as potentially possessing critical thresholds, sometimes referred to as tipping points (Lenton et al., 2008)), beyond which abrupt or nonlinear transitions to a different state ensue. The term irreversibility is used in various ways in the literature. [...] Here, we also assess aspects of irreversibility in the context of abrupt change, multiple steady states and hysteresis, i.e., the question whether a change (abrupt or not) would be reversible if the forcing was reversed or removed (AR5 WG1: 1114) 
Figure 1: Suggested mapping for the tipping point metaphor in climate science

\section{Source domain: space change}

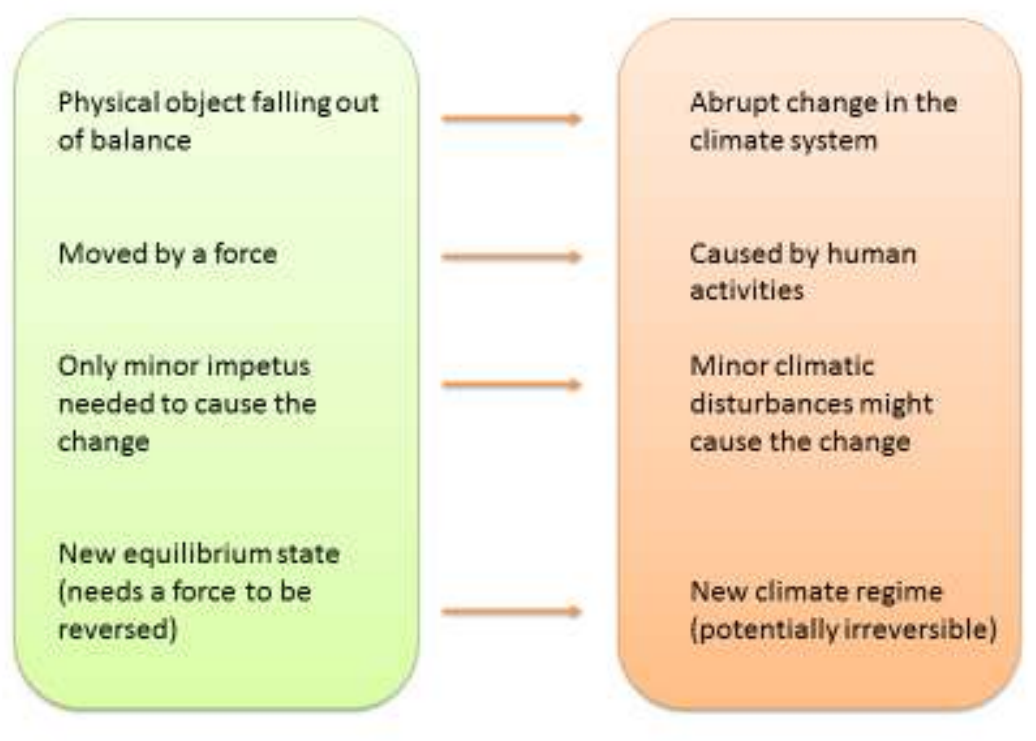

The vividness of the image conjured up by the word "tipping point" therefore lingers in its uses as a metaphorical term and suggests that its metaphorical nature may still be active in the domain of climate science, at least in some contexts. Another hint that some of the IPPC contributors still see "tipping point" as metaphoric is their use of punctuation. In AR5, for instance, the report on the physical basis of climate science contains 8 occurrences of "tipping point(s)" in quotation marks (out of 88 hits), which seems unusual for a term chosen as an entry in the glossary ${ }^{6}$. In order to gain a more precise view of "tipping point(s)" in the IPCC reports, though, we need to monitor their use in the five assessment reports, throughout the 1990-2014 period.

A concordance search for "tipping point*" in the IPCC reports yields puzzling results: there were no occurrences of "tipping point(s)" at all in AR1, AR2 or AR3, 15 hits for AR4 in 2007 and 146 for AR5 in 2014 (see Table 4).

Table 4: Occurrences of "tipping points" in the IPCC reports

\begin{tabular}{|l|l|l|l|l|l|}
\hline & AR1 (1990) & AR2 (1995) & AR3 (2001) & AR4 (2007) & AR5 (2014) \\
\hline WG1 & 0 & 0 & 0 & 4 & 27 \\
\hline WG2 & 0 & 0 & 0 & 9 & 105 \\
\hline WG3 & 0 & 0 & 0 & 2 & 5 \\
\hline synthesis & 0 & 0 & 0 & 0 & 9 \\
\hline total & 0 & 0 & 0 & 15 & 146 \\
\hline
\end{tabular}


seems to be a clear-cut case of a "lexical fracture" here, ie. the sudden appearance (or disappearance) of a specific term in a corpus, often referring to historical events in a specialised domain or in the world at large (see Dury 2018: 80-95). In fact, the term "tipping point" was originally used in social science to apply to sudden racial changes in a given urban or suburban area (Grodzins 1957). It was then popularised as a social phenomenon by Malcolm Gladwell's best seller: The Tippingpoint: how little things can make a big difference (2000). Gladwell started from the already conventional meaning of "tipping point" in the medical context "that one dramatic moment in an epidemic when everything can change all at once..." (Gladwell 2000: 9) and extended it to social ideas and trends: "that magic moment when an idea, trend, or social behaviour crosses a threshold, tips, and spreads like wildfire" (ibid.: 12). Russill and Nyssa, who researched the highbrow press in the US and the UK, found the first use of "tipping point" in 2002 for the UK and 2003 for the US, within the context of climate change (2009: 339). A major change occurred in 2005 when James Hansen, a well-known climate scientist, stated in a presentation to the American Geophysical Union "We are on the precipice of climate system tipping points beyond which there is no redemption" (Hansen 2005: 8). This statement, which contains both spatial and religious metaphors, first found an echo in the press, and only later in research articles, as Steen and colleagues, who monitored the use of "tipping point(s)" in a press corpus and the Web of Science, found out. Their research, which spans the 2005-2014 period, shows only four research articles mentioning "tipping point" in their titles in 2005-6, as opposed to 74 press articles, whereas this trend was reversed for 2013-14, with 125 research papers and only 49 newspaper articles published (Van der Hel et al 2018: 610).

This historical background can account for the reason why there was no mention of "tipping points" in the IPCC reports before 2007. The rising trend of research publications points to the choice of "tipping point" as a term in its own right by climate scientists and is a clue that it is developing into a theory-constitutive metaphor. However, the fact that it became popular in the general press before it was adopted by climate scientists seems to indicate some sort of questioning within the climate science community over whether it was appropriate or not to adopt this metaphor in climate science. adaptation limits including "thresholds" (Meze-Hausken, 2008; Briske et al., 2010; Washington-Allen et al., 2010) or

regime shifts (Washington-Allen et al. 2010)

tipping points (Lenton et al. 2008; Kriegler et al. 2009)

dangerous climate change (Mastrandrea \& Schneider 2004; Ford 2009a)

reasons for concern (Smith et al. 2009a)

planetary boundaries (Rockström et al. 2009)

key vulnerabilities (Schneider et al. 2007; Hare et al. 2011; Johannessen \& Miles 2011; see also Section 19.6). (AR5 WG2A: 919)

In the quotation above, "tipping points" are placed within the frame of adaptation limits, along with six neighbouring terms. Within AR5, more than a quarter of "tipping point(s)" hits (28 out of 88 , excluding references), were accompanied with at least one 
of the other terms listed above, which confirms the claim that they can function as alternatives. The following example is a case in point:

Recent studies have provided valuable insights regarding global "tipping points," "key vulnerabilities," or "planetary boundaries" as well as evidence of climate thresholds for agricultural crops, species of fish, forest and coral reef communities, and humans. (AR5 WG2A: 902)

Concordance results for these alternatives show a definite upward trend from 1990 to 2014, rising from only one hit for AR1 to 460 occurrences in AR5 (see Table 5). "Reasons for concern" first appeared in AR1, "critical thresholds" and "regime shifts" in AR2, "dangerous climate change" and "key-vulnerabilities" in AR3, "tipping points" in AR4 and "planetary boundaries" in AR5. Leaving aside "key vulnerabilities" which is both a euphemism and an umbrella term referring to a much wider range of environmental issues, "tipping points" appears as the most frequent alternative in AR5, which is another clue that it has become a theory-constitutive metaphor in climate science.

Table 5: Alternatives to adaptation limits in AR1 to AR5

\begin{tabular}{|l|l|l|l|l|l|l|}
\hline & AR1 (1990) & AR2 (1995) & AR3 (2001) & AR4 (2007) & AR5 (2014) & Total \\
\hline critical thresholds & 0 & 3 & 12 & 5 & 23 & 43 \\
\hline regime shifts & 0 & 1 & 4 & 5 & 27 & 37 \\
\hline tipping points & 0 & 0 & 0 & 15 & 146 & 161 \\
\hline dangerous climate change & 0 & 0 & 3 & 69 & 30 & 102 \\
\hline reasons for concern & 1 & 0 & 106 & 20 & 75 & 202 \\
\hline planetary boundaries & 0 & 0 & 0 & 0 & 9 & 9 \\
\hline key vulnerabilities & 0 & 0 & 8 & 185 & 150 & 343 \\
\hline Total & 1 & 4 & 133 & 299 & 460 & 897 \\
\hline
\end{tabular}

If we now analyse all the alternatives to "tipping points' from the point of view of cognitive semantics, we can notice that "critical thresholds", "planetary boundaries" and "regime shift" (as well as adaptation limits) are also space metaphors. They can all be explained via a source-path-goal image schema, in which the source is the preindustrial era taken as a reference point, the goal mirrors a dystopic future, and the path represents human lives (see Figure 2). On this image schema, the limits, thresholds, boundaries and tipping points are all represented by a vertical line, symbolising a barrier which cannot be crossed without serious consequences. 
Figure 2: Space metaphors as alternatives to "adaptation limits" in AR1 to AR

source-path-goal image schema:

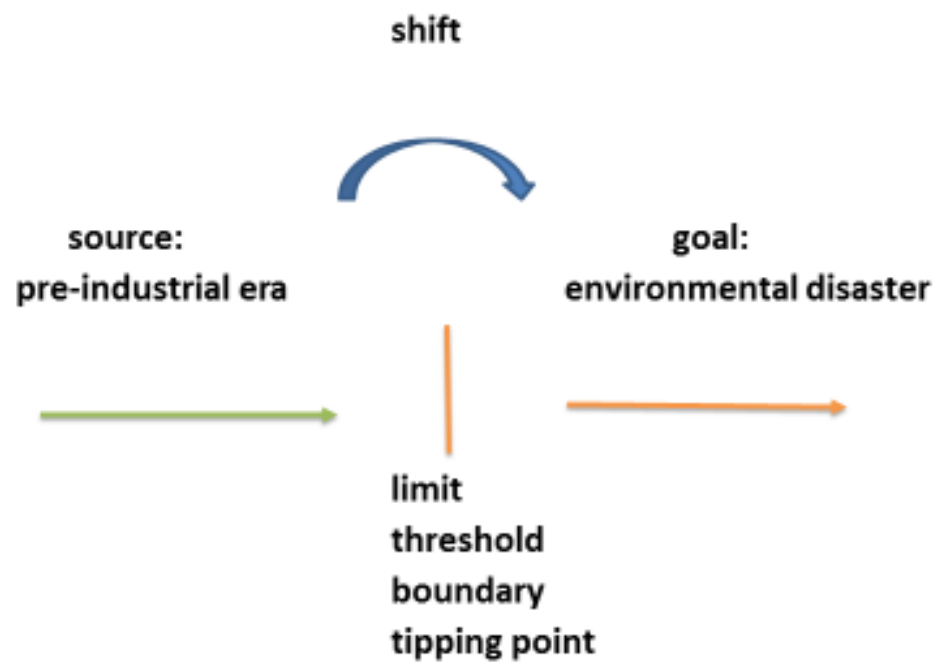

However, concordance lines also provide clues about the specificity of "tipping points". First, they appear as more dramatic than climate thresholds, adaptation limits or planetary boundaries, because, instead of highlighting the borderline between two separate climatic regimes, they focus on the very moment of change (in a much more fast-paced way than regime shift, which can take time). This is reflected in occurrences such as "tipping points of disastrous climate change impacts" (WG3: 1015) or "many estimates do not account for catastrophic changes, tipping points, and many other factors" (AR5 WG2: 663). Secondly, tipping points are more threatening because their defining characteristics, unlike boundaries, limits, thresholds or shifts, are abruptness and potential irreversibility, as shown in the following occurrences: "tipping points, thresholds of abrupt and irreversible change" (AR5 WG2: 14) or "With increasing warming, some physical systems or ecosystems may be at risk of abrupt and irreversible changes. Risks associated with such tipping points..." (AR5 WG2A: 61).

The abrupt and irreversible characteristics of tipping points have clear deontic significance from the general point of view of environmental ethics. As the detection of their presence and location remains "a major source of uncertainty with high potential consequences" (AR5 WG2: 328), like "black swans" in economics, it is part of the IPCC duties to inform both the policy makers and the general public about what they might result in. The following passage gives an example of such warnings:

Under $4^{\circ} \mathrm{C}$ warming most of the world land area will be experiencing $4^{\circ} \mathrm{C}$ to $7^{\circ} \mathrm{C}$ higher temperatures than in the recent past, which means that important tipping points for health impacts may be exceeded in many areas of the world during this century, including coping mechanisms for daily temperature/humidity, seasonally compromising normal human activities, including growing food or working outdoors. (AR5 WG2: 1063)

The likelihood of tipping points is a vexed question, however, because they are nonlinear phenomena and therefore quite difficult to include in the current climate 
models, as acknowledged in the technical summary for the report of the second working group:

Global economic impacts from climate change are difficult to estimate. Economic impact estimates completed over the past 20 years vary in their coverage of subsets of economic sectors and depend on a large number of assumptions, many of which are disputable, and many estimates do not account for catastrophic changes, tipping points, and many other factors. (AR5 WG2A: 19)

In other words, "tipping points" appear as an epistemic as well as a deontic issue in AR5 and defining physical phenomena as "tipping points" requires caution, as the following quotations remind us: "there is no evidence for global-scale tipping points in any of the most comprehensive models evaluated to date in studies of climate evolution in the 21st century" (AR5 WG1: 129) or

[t]here is little evidence in global climate models of a tipping point (or critical threshold) in the transition from a perennially ice-covered to a seasonally ice-free Arctic Ocean beyond which further sea ice loss is unstoppable and irreversible. (AR5 WG1: 92)

The epistemic uncertainty linked with "tipping points", added to the deontic imperative of fighting abrupt and irreversible changes in the climate system, therefore fuels an ethical dilemma. If the likelihood of tipping points is presented as high and the magnitude of the problem discourages both policy makers and the general public, it may induce global apathy, which would defeat the IPCC objectives. On the other hand, failing to give early warning as soon as possible may deprive mitigation policies from a powerful incentive. The report of the Third Working Group shows how this ethical dilemma is echoed in the scientific literature:

Earlier research suggested that reducing uncertainty about the benefits and costs of mitigation can render IEAs less effective, showing that as parties learn of the actual costs and benefits of mitigation, their incentive to participate may shrink ( $\mathrm{Na}$ and Shin, 1998; Kolstad, 2005; Kolstad and Ulph, 2008). However, more recent work (Finus and Pintassilgo, 2012, 2013; Dellink and Finus, 2012) has qualified this conclusion by showing that removing uncertainty only has a negative impact on cooperation in certain cases. Recent experimental evidence suggests that if there is uncertainty in the likelihood of tipping points of disastrous climate change impacts, this may reduce the success of cooperation (Dannenberg et al., 2011); conversely, reducing uncertainty about the likelihood of tipping points can increase prospects for collective action (Barrett and Dannenberg, 2012). (AR5 WG3: 1015)

\section{Conclusion}

If we now come back to our initial research questions, a corpus study of the five IPCC reports has shown that their explicit ethical approach is increasingly expressed as such, although it remains fairly general and abstract. On the other hand, the metaphorical terms used can also convey ethical issues implicitly, in a more concrete way. The "tipping point" metaphor is a good example of this implicit ethical approach, because it is a case of lexical fracture caused by ethical issues expressed in a both deontic and epistemic way. Its sudden appearance in AR4 implied a change in terminology rather than a new discovery and its use was a "wake up call", motivated by a wish to frame the most alarming aspects of climate change in a way that would induce political action. In other words, the use of "tipping point" in climate science was first motivated by ethical and political reasons before it became constitutive of theories in that research field. The example of "tipping points" thus clearly shows that 
metaphorical terms can function both as a tool for peer-to-peer communication in specialised domains and a bridge between science and the general public, as highlighted by Catherine Resche:

Metaphorical terms cannot be ignored either for the roles they play as vehicles of new ideas and viewpoints, as mediators between scientists and their peers, but also as intermediaries between specialists and non-scientists. (Resche 2013:134)

In the context of the IPCC reports, metaphorical terms can be an entrance door into theories in both ethics and climate change, helping us to understand the issues at hand and pin down the ethical challenges to which they are linked.

I would like to thank Camille Biros for drawing my attention to the "tipping point" metaphor, Natasha Wilcke for insisting on the importance of professional ethics and proof reading the final version of this paper and, finally, the two anonymous reviewers for suggesting ways of developing a linguistic view of professional ethics.

\section{BIBLIOGRAPHY}

BIROS, Camille. 2010. « Premiers éléments de définition d'un type émergent de FASP: l'ecothriller ». ASp 57, 67-85.

BIROS, Camille. 2018. "Nurturing the wealth beneath our feet or trampling sacred grounds? Blog narratives on fossil fuel development in New Zealand 2010-2016". ILCEA 31. DOI: 10.4000/ilcea. 4678.

BOYD, Richard. 1993 [1979]. "Metaphor and theory change: What is 'metaphor' a metaphor for?". In Ortony, A. (ed.), Metaphor and Thought. Cambridge: Cambridge University Press, 481-532. BROECKER, Wallace Smith. 1975. "Climatic change: Are we on the brink of a pronounced global warming?”. Science 189/4201, 460-463.

DEIGNAN, Alice. 2017. “Metaphors in texts about climate change”. Iberica 34, 45-66.

DURY, Pascaline. 2018. "La dimension diachronique en anglais de spécialité : une approche terminologique”. Rapport de synthèse, université Lyon 2.

FLøTtUM, Kjersti. 2014. "Linguistic mediation of climate change discourse”. ASp 65, 7-20.

FLøTTUM, Kjersti. 2017. The Role of Language in the Climate Change Debate. New York: Routledge.

FRIES, Marie-Hélène. 2016. Nanomonde et nouveau monde : quelques métaphores-clés pour analyser le discours sur les nanotechnologies aux États-Unis. Grenoble : Éditions littéraires et linguistiques de l'université de Grenoble.

FRIES, Marie-Hélène. Forthcoming. “Termes métaphoriques et domaines spécialisés : le cas du changement climatique". Paris : Éditions des archives contemporaines.

GARDINER, Stephen. 2011. A Perfect Moral Storm: The ethical challenge of moral change. Oxford: Oxford University Press. 
GLADWELL, Malcolm. 2000. The Tipping Point: How little things can make a big difference. Boston, MA: Little Brown and Company.

GRODZINS, Morton. 1957. "Metropolitan segregation”. Scientific American 1974, 33-41.

HANSEN, James E. 2005. “Is there still time to avoid 'dangerous anthropogenic interference' with global climate?". Presentation on December 6, 2005 at the American Geophysical Union, San Francisco, CA, retrieved from <http://www.columbia.edu/ jeh1/2005/Keeling_20051206.pdf> on $15 / 02 / 2019$.

HULME, Mike. 2009. Why We Disagree About Climate Change: Understanding Controversy, Inaction and Opportunity. Cambridge: Cambridge University Press.

IPCC. Intergovernmental Panel on Climate Change, consulted 15 February $2019<$ https:// www.ipcc.ch>.

LAKOFF, George \& Mark JOHnson, 1999. Philosophy in the Flesh. Chicago: Chicago University Press.

PETIT, Michel. 2010. « Le discours spécialisé et le spécialisé du discours : repères pour l'analyse du discours en anglais de spécialité », E-rea 8/1, DOI : 10.4000/erea.1400.

PEYNAUD, Caroline. 2018. "La notion de climat dans le discours de la presse anglophone: le traitement de la question climatique de 2010 à 2017". ASp 74, 77-93.

Pragglejazz group. 2007 "MIP: A method for identifying metaphorically used words in discourse". Metaphor and Symbol 22/1, 1-39. DOI: 10.1080/10926480709336752.

RESCHE, Catherine. 2012. "Towards a better understanding of metaphorical networks in the language of economics: The importance of theory-constitutive metaphors". In HERRERA-SOLER, H. \& M. WHITE (eds.), Metaphors and Mills. Berlin: Mouton de Gruyter, 77-102.

RESCHE, Catherine. 2013. Economic Terms and Beyond: Capitalising on the Wealth of Notions. Bern: Peter Lang.

RICœUR, Paul. 1990. Soi-même comme un autre. Paris: Seuil.

RossI, Micaela. 2015. In rure alieno, Métaphores et termes nomades dans les langues de spécialité. Bern: Peter Lang.

RUSSILL, Chris \& Zoe NYSSA. 2009 "The tipping point trend in climate change communication". Global Environmental Change 19, 336-344.

SHAW, Christopher \& Brigitte NERLICH. 2015. "Metaphor as a global mechanism of climate change governance: A study of international policies, 1992-2012”. Ecological economics 109, 34-40.

VAN DER HeL, Sandra, Lina HELLSTEN \& Gerard STEEN. 2016. “Tipping points and climate change: Metaphor between science and the media", Environmental Communication 12/5, 605-20.

WOZNIAK, Séverine and Camille BIROs (eds.). 2016. "Special issue on specialised discourse and language on energy, ecology and environment”. Progress in Industrial Ecology, an International Journal 10/2-3, 115-116.

\section{NOTES}

1. The term "deontic" has been preferred to "deontological" in this article, because deontological ethics, in philosophy (from the Greek $\delta$ ćov, deon, meaning obligation, duty), has a precise definition. It refers to the morality of an action in absolute terms, by evaluating it according to 
prescriptive rules, unlike sequentialist ethics, which judges the morality of an action according to the consequences involved. In contrast, deontic modality, in linguistics, is also linked to a system of rules, but is generally opposed to epistemic modality, which focuses on probability with regard to knowledge. As the IPCC is a scientific body giving "policy-relevant" recommendations, the dichotomy between epistemic and deontic seems the most relevant in the context of their reports.

2. See for example AR5 WG3: 215.

3. The IPCC publishes three types of work: Assessment Reports, Special Reports and Methodology Reports. However in this paper, "IPCC reports" refer to the Assessment Reports only. Each individual report is referred to according to the terminology adopted by the IPCC, e.g. AR1 is short for the first Assessment Report and WG1 for the first Working Group.

4. Un domaine spécialisé est constitué autour et en vue d'une activité principale, qui définit sa place reconnaissable au sein de la société.

5. However, deontology has not been included, because it exclusively refers to a branch of philosophy in English, unlike déontologie in French, which means "professional ethics."

6. In contrast, the same report also contains 58 references including "tipping point(s)" in their titles, only two of them within quotation marks.

\section{ABSTRACTS}

Climate change is a both a cause of concern (in the English-speaking world and beyond) and a wide-ranging field of research, situated at the crossroads between science and technology, economics and politics. It is linked to major socio-scientific controversies, in which issues linked with ethics play a major role, from a deontic as well as an epistemic perspective. The main objective in this article is to explore the ethical points of view expressed in the Assessment Reports of the International Panel on Climate Change (IPCC) both explicitly, through the occurrences of the words "ethics", "morals" and their derivatives, and implicitly, through the use of the metaphorical terms contained in the IPCC reports. Terms based on metaphors constitutive of climate change theories are focused on, in order to examine in which ways they can express ethical values implicitly. This perspective is developed with the example of "tipping points".

Le changement climatique est à la fois une cause de préoccupations (dans le monde anglophone et au-delà), et un large secteur de recherche situé au carrefour des sciences et technologies, de l'économie et de la politique, Il est lié à des controverses socio-scientifiques importantes, dans lesquelles les questions d'éthique jouent un rôle essentiel, d'un point de vue déontique aussi bien qu'épistémique. L'objectif de cet article est d'explorer les points de vue éthiques exprimés dans les rapports d'évaluation du Groupe International d'Études sur le Climat (GIEC), à la fois de façon explicite, à travers l'usage des mots "éthique ", "morale» et de leurs dérivés, mais aussi de façon implicite, à travers l'utilisation des termes métaphoriques contenus dans les rapports du GIEC. L'accent est mis sur les termes métaphoriques fondés sur des métaphores constitutives des théories liées au changement climatique, Cette perspective est développée, avec l'exemple des " points de bascule ». 
INDEX

Mots-clés: changement climatique, éthique environnementale, GIEC, métaphore, point de bascule, terme métaphorique

Keywords: climate change, environmental ethics, IPCC, metaphorical term, metaphor, tipping point

\section{AUTHOR}

MARIE-HÉLÈNE FRIES

Marie-Hélène Fries teaches scientific English at the University of Grenoble-Alpes, France. Her research interests are focused on the uses of metaphors in scientific discourse, ranging from scientific articles to science-fiction. She has published a book on metaphors linked to nanotechnology in the US (Nanomonde et Nouveau Monde, 2016). marie-helene.fries@univgrenoble-alpes.fr 